\title{
O protagonismo de Ellen G. White no projeto educacional cristão adventista no Brasil
}

\author{
Ellen G. White's Lead Role in the Adventist Christian \\ Educational Project in Brazil \\ El papel de Ellen $G$. White en el proyecto educativo \\ cristiano adventista en Brasil
}

Giza Guimarães Pereira Sales (iDa

ROSANE MicheLLI DE CASTRO (iD

\section{Resumo}

O presente artigo é decorrente de pesquisa histórica, centrada em análise documental e bibliográfica e tem como objetivo demonstrar como Ellen G. White (1827-1917), escritora norte-americana, exerceu papel preponderante no desenvolvimento e estabelecimento dos princípios da educação adventista do sétimo dia. Pioneira e uma das fundadoras do movimento, iniciado por volta de 1844, com seus conselhos e orientações através de artigos, manuscritos, cartas e livros, estabeleceu as diretrizes filosóficas educacionais do sistema educacional, doutrinárias da instituição como igreja e de saúde da instituição, que visa o bem-estar de seus seguidores e de tantos quantos possam ser beneficiados. Com isso, aquilo que, no início era apenas um movimento religioso, se consolida em uma instituição confessional de orientação protestante, cuja presença se estende

\footnotetext{
${ }^{a}$ Universidade Estadual Paulista (UNESP), Marília, SP, Brasil; Centro Universitário Adventista de São Paulo (UNASP), Engenheiro Coelho, SP, Brasil. Doutorado em educação, e-mail: giza.sales@gmail.com.

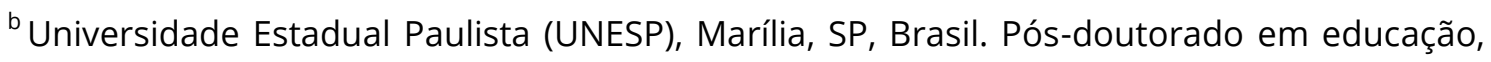
e-mail: rosanemichelli@marilia.unesp.br.
} 
a várias partes do mundo, destacando-se no campo educacional por meio de suas escolas e internatos que atuam desde o ensino básico até o superior, bem como por ampla rede de hospitais e clínicas médicas. Seus escritos sobre educação de crianças e jovens, saúde, temperança e vida cristã constituem a base da filosofia cristã adventista e têm servido como orientações para os fiéis frente às incertezas da vida secular até os dias atuais.

Palavras-chave: Ellen G. White. Educação cristã adventista. Protagonismo feminino.

\section{Abstract}

This paper deals with the results of historical research, centered on documentary and bibliographic analysis, and aims to demonstrate how Ellen G. White (1827-1917), an American writer, played a leading role in the development and establishment of the principles of Seventh-day Adventist education. A pioneer and one of the founders of the movement that began around 1844, with her advice and guidance through articles, manuscripts, letters and books, she established the educational philosophical guidelines of the educational system, the doctrinal of the institution as a church, and the health of the institution, that aims at the welfare of its followers and as many as it may benefit. With that, what was initially just a religious movement is consolidated in a confessional institution of Protestant orientation, whose presence extends to various parts of the world, stands out in the educational field through its schools and boarding schools that operate from basic to higher education, as well as a wide network of hospitals and medical clinics. His writings on the upbringing of children and youth, health, temperance, and Christian life form the basis of the Adventist Christian philosophy and have served as guidelines for the faithful in the face of the uncertainties of secular life to the present day.

Keywords: Ellen G. White. Adventist Christian education. Female protagonism.

\section{Resumen}

Este artículo resulta de investigaciones históricas, orientadas en el análisis documental y bibliográfico, y tiene por objetivo demostrar cómo Ellen G. White (1827-1917), una escritora estadounidense, desempeñó un papel de liderazgo en el desarrollo y el establecimiento de los principios de la educación adventista del séptimo día. Pionera y una de las fundadoras del movimiento, iniciado alrededor de 1844, con sus consejos y orientaciones a través de artículos, manuscritos, cartas y libros, estableció los lineamientos filosóficos educativos del sistema educacional, doctrinarios de la institución como iglesia y la salud de la institución que apunta al bienestar de sus seguidores y de todos los que puedan beneficiarse. Con eso, lo que inicialmente era solo un movimiento religioso, se consolida en una institución confesional de orientación protestante, cuya presencia se extiende a varias partes del mundo, destacándose en el campo educativo a través de sus escuelas y internados que operan desde la educación 
básica a la superior, así como una amplia red de hospitales y clínicas médicas. Sus escritos sobre la educación de niños y jóvenes, la salud, la templanza y la vida cristiana forman la base de la filosofía cristiana adventista y han servido como orientaciones para los fieles frente a las incertidumbres de la vida secular hasta nuestros días.

Palabras clave: Ellen G. White. Educación cristiana adventista. Protagonismo femenino.

\section{Introdução}

Trata o presente artigo de pesquisa histórica, centrada em análise documental e bibliográfica, e tem como objetivo demonstrar como Ellen G. White (1827-1917), escritora norte-americana, exerceu papel preponderante no desenvolvimento e estabelecimento dos princípios da educação adventista do sétimo dia. O referencial teórico-metodológico para a investigação está subsidiado nos pressupostos de análise da História Cultural (CHARTIER, 1990; CERTEAU, 1982; BURKE, 2011) em busca de compreender aspectos de uma determinada realidade, articulando a percepção dos fatos por seus diferentes sujeitos, relacionando-os com o conjunto de documentos e bibliografia específica que tematizam ou se aproximam do objeto estudado.

Para a realização das nossas investigações foram feitas consultas a bases de dados disponíveis on-line e sites da internet ligados aos diversos arquivos de instituições de pesquisa, além de consulta física aos acervos das bibliotecas da FFC-UNESP-Marília, FE-USP-São Paulo, FE-Unicamp-Campinas e bibliotecas do Centro Universitário Adventista de São Paulo-UNASP e Centro Nacional da Memória Adventista, localizados nas cidades de São Paulo e Engenheiro Coelho.

Por meio desse trabalho constatamos que há investimentos dos historiadores sobre a influência das instituições protestantes e o desenvolvimento educacional no Brasil. Dentre eles, destacam-se: Ramalho (1976), Barbanti (1977), Léonard (1981), Mendonça (1990), Reilly (1984), Hack (1985), Boaventura (1978), Schulz (2003), Calvani (2009) e Vieira (1996).

Segundo esses pesquisadores, os protestantes vieram principalmente da Europa com o objetivo de buscar novas oportunidades de vida e trabalho e de firmar raízes em solo brasileiro, considerado terra promissora, aberta ao recebimento de mão de obra imigrante. Paralelamente ou conjuntamente a esses 
propósitos, havia ainda imigrantes com o intento evangelístico de propagação de suas doutrinas a regiões ainda não alcançadas pela fé protestante. É nessa modalidade de imigração, para propagação de ideais religiosos, que os adventistas saídos principalmente dos Estados Unidos da América chegam ao Brasil, país considerado, naquele momento, com nenhuma ou com pouca representatividade adventista na América do Sul.

No Brasil, a educação cristã adventista surge no momento de propagação das ideias protestantes trazidas pelos imigrantes europeus e americanos, dentre as quais ressaltaram o liberalismo, pragmatismo e individualismo norte-americanos que ganharam o mundo e acabaram se disseminando no final do século XIX. Essas influências circulavam tanto no campo das ideias, da política, da economia, como também da educação. Nesse sentido, é possível afirmarmos que os protestantes norte-americanos, além da pregação das suas doutrinas, influenciaram significativamente a educação brasileira, na medida em que vislumbravam a educação como forma de ascensão para um nível intelectual mais avançado. Partindo dessa concepção, cada crente deveria ser capaz de ler, compreender e seguir os ensinamentos bíblicos a partir do seu próprio entendimento. Com isso, onde passavam, criavam igrejas, escolas e colégios, chegando a estabelecer uma rede de instituições confessionais de caráter cristão protestante que viria, de certa forma, modificar o cenário educacional brasileiro.

Entretanto, Stencel (2004) afirma que não se pode considerar a solidez da obra educacional adventista sem considerar os escritos e a influência de Ellen White. Daí a constituição deste texto sobre o protagonismo de Ellen G. White na educação cristã adventista brasileira e mundial.

\title{
A filosofia educacional adventista e o papel de Ellen G. White
}

\author{
Conforme menciona Knight (1983, p. 26) \\ É impossível compreender a educação adventista, quer atual ou histórica, sem \\ entender o papel e o impacto de Ellen White sobre esse desenvolvimento. Ela não
}


foi apenas a figura central nesse desenrolar, mas a única líder adventista que se distinguiu desde o início até o fim do período formativo.

As suas influências parecem ultrapassar as fronteiras da organização adventista e se prolongar na história, conforme apontam Gross \& Gross (2012), quando se referem à repercussão mundial dos escritos de White ${ }^{1}$ (p. 13): "Ellen G. White está entre os autores norte-americanos mais traduzidos de todos os tempos e é também a autora feminina mais traduzida no mundo, sendo suas obras disponíveis em mais de cento e cinquenta idiomas".

Sobre a importância da educação no sistema teológico-doutrinário adventista, vê-se que a educação e religião não são coisas distintas. Estão intimamente ligadas pelo objetivo comum, conforme aponta Menslin (2015, p. 10):

Contudo, a principal razão de existir um sistema mundial como é a educação adventista, vai muito mais além do que o interesse de proporcionar uma educação com qualidade ou mesmo uma educação que esteja cumprindo com os objetivos estabelecidos por políticas públicas ou métodos reguladores de avaliação. 0 objetivo de uma denominação religiosa manter um sistema integrado de educação está no fato de acreditar que a educação é a própria igreja, pois tanto a igreja como a escola visam o mesmo fim - salvação do ser humano, transformando-o a semelhança e imagem de seu Criador.

Distante no tempo em aproximadamente 40 anos, os princípios de White, adotados pelo sistema adventista a partir de 1872, apresentam semelhanças com o

\footnotetext{
${ }^{1}$ O livro Caminho a Cristo [Step to Christ], de Ellen G. White, já foi traduzido em mais de 120 idiomas e a tiragem no Brasil ultrapassa 6,8 milhões de exemplares. <https://www.cpb.com.br/produto/detalhe/7666/caminho-a-cristo>. Acesso em: 01 jun. 2018. À época de sua morte, a produção literária de Ellen White totalizava aproximadamente 100.000 páginas: 24 livros em circulação; dois manuscritos de livros prontos para publicação; 5.000 artigos em periódicos da igreja; mais de 200 tratados e panfletos; aproximadamente 35.000 páginas datilografadas de documentos e cartas manuscritas; 2.000 cartas escritas à mão e diários, que resultaram, quando copiados, em outras 15.000 páginas datilografadas. As compilações dos escritos de Ellen White feitas após a sua morte totalizam um número de mais de 130 livros em circulação. Disponível em: $<$ http://www.centrowhite.org.br/perguntas/perguntas-sobre-ellen-g-white/os-escritos-de-ellen-g-white/> . Acesso em: 01 jun. 2018.

A revista americana Smithsonian Magazine, na edição de 17 de novembro de 2014, publicou uma pesquisa sob o título "Os 100 americanos mais significantes de todos os tempos" ("The 100 Most Significant Americans Of All Time") e dentre os religiosos aparece o nome de Ellen G. White. Disponível em: <https://www.smithsonianmag.com/smithsonianmag/meet100-most-significant-americans-all-time-180953341/?no-ist>. Acesso em: 01 jun. 2018.
} 
que, em 1833, era fundamento do Instituto Oberlin ${ }^{2}$, instituição metodista, no estado de Ohio (EUA) que visava o cuidado ao corpo, coração e mente, centrando atenção na melhor educação do homem integral (KNIGHT, 1983, p. 164): “O sistema educacional neste Instituto se propõe a cuidar do corpo e do coração bem como do intelecto; pois visa a melhor educação do ser humano como um todo" (KNIGHT, 2004, p. 1). A importância do trabalho manual, tanto para a saúde como para o custeio de despesas dos alunos, a reforma de saúde através do uso de alimentos naturais, eliminação de álcool e fumo, a adoção de dieta vegetariana, o evitar alimentos entre as refeições, a prática de exercícios físicos, o repouso adequado, a forte ênfase na espiritualidade, o não uso de literatura ficcional nociva, inclusive dos clássicos da literatura, considerados como influenciadora para os jovens, são todos princípios da educação e modo de vida adventista que estavam presentes também no pensamento do Instituto Oberlin (KNIGHT, 2004, p. 2).

Conquanto acredita-se que White tenha recebido inspiração divina para escrever e sintetizar princípios educacionais, é possível observar que o conteúdo de seus escritos, mormente no livro Educação, não está dissociado de todo um contexto filosófico de sua época (GROSS; GROSS, 2012). Em seu momento histórico, circulavam conceitos decorrentes do ressurgimento das ideias de educação integral, já preconizadas por Rousseau e Condorcet que destacavam a bondade natural do homem, a vivência em meio à natureza e afastamento das cidades para o pleno desenvolvimento das faculdades mentais. Para Rousseau, as cidades são local degeneração em que o homem se afasta de seu estado de pureza original, da forma como saiu das mãos do criador. Em outras palavras, o pensamento de Rousseau,

\footnotetext{
${ }^{2}$ Fundado pelo Reverendo John J. Shipherd em 1833, no nordeste de Ohio, a Colônia e Escola de Oberlin teve como objetivo inicial preparar professores e missionários para trabalharem no então desolado Oeste americano. Adotando como inspiração primeira o pietismo, apesar de seu conservadorismo, o Oberlin tomou algumas medidas progressistas para a época, como a luta contra a escravidão, a admissão de alunos negros e a coeducação, sendo a primeira instituição da América a conferir o grau de Bacharel a mulheres.

Outras práticas educacionais consideradas inovadoras para a época foram: a educação integral, que envolve o físico, o mental e o espiritual; reforma nos hábitos de saúde, sobretudo no que diz respeito à alimentação, incluindo a dieta vegetariana; currículo centrado na Bíblia com forte crítica aos autores clássicos; instituições educacionais localizadas na zona rural e preocupação com as demais reformas sociais. O Oberlin College foi a referência principal para a constituição da filosofia educacional Adventista. Disponível em: <http://www.histedbr.fe.unicamp.br/navegando/gl ossario/verb_c_oberlin_college.htm>. Acesso em: 01 jun. 2018.
} 
neste aspecto, é o de que o homem é naturalmente bom, mas a sociedade o corrompe. Acrescentam-se ainda as influências de Kant, sobre o retorno ao ambiente natural, e de Pestalozzi, sobre a valorização do trabalho educativo com uso das mãos, do corpo e da mente, promovendo aquilo que hoje chamamos educação integral. Embora existam diferenças substanciais em relação aos objetivos educacionais entre White e esses filósofos, é possível perceber aproximações (GROSS; GROSS, 2012; STENCEL, 2006; SALES, 2019).

O primeiro escrito de White, considerado pelos adventistas como de inspiração divina, traçando princípios educacionais, é de 1872 (SCHWARZ; GREENLEAF, 2009), intitula-se “A Verdadeira Educação" ou "A Devida Educação", cujo título original é "Proper Education". Nesse texto a autora esclarece que a educação apropriada vai além do desenvolvimento harmonioso de todas as faculdades humanas — físicas, morais e espirituais — mas tem como fim "[...] restaurar o homem à imagem do seu Criador".

Sua declaração sobre "A Devida Educação" possui três seções. A primeira tem a ver com a importância da educação, a diferenciação entre educação e treinamento e a exposição da disciplina como como autodomínio. A segunda fala da educação física e do trabalho manual com relação à educação tanto no lar como na escola. É no final dessa seção que a senhora White afirma que os adventistas devem ser "reformadores educacionais". Finalmente, a terceira seção considera o ensino da Bíblia e as áreas comuns para aqueles que se preparam para o ministério (STENCEL, 2004, p. 13).

Ellen White e seu esposo Thiago White idealizavam uma escola campestre com espaço para o cultivo de plantas e contato com a natureza. Medidas foram tomadas para adquirir uma propriedade em Battle Creek (Virgínia, EUA) onde a primeira escola de ensino básico confessional adventista foi inaugurada em 03 de junho de $1872^{3}$.

Ellen White escreveu mais três livros que tratam especificamente sobre princípios e conselhos educacionais: Educação (1903), Conselhos aos Professores, Pais e

\footnotetext{
${ }^{3}$ Parte da propriedade foi desmembrada para construção de um hospital, deixando a escola sem o espaço suficiente para aquilo que White pretendia. Em 1901 a escola foi transferida para Berrien Springs, Michigan, local onde atualmente se encontra a Universidade Andrews, primeira instituição adventista de Ensino Superior.
} 
Estudantes (1913) e Fundamentos da Educação Cristât (1923). Como mencionado em site sobre a respeito da vida e obra da autora,

Ao buscar os conselhos de Ellen G. White em seus escritos sobre escolas adventistas, seu currículo, normas e trabalho, facilmente se observa que raramente ocorre uma distinção entre os diferentes graus escolares. Tais linhas divisórias não eram então perfeitamente estabelecidas como o são hoje nas instituições educacionais em geral. No que nos diz respeito, a educação elementar veio por último, com uma séria iniciativa tomada na virada do século dezenoves.

Os escritos de Ellen G. White foram fundamentais para construção dos ideais e da filosofia adventista de educação. Também influenciou a estrutura organizacional das escolas e da administração das instituições adventistas, como também escreveu orientações sobre outras áreas consideradas importantes para o bom andamento da vida do cristão.

Com base em tais ideias, o sistema educacional adventista nasceu e se desenvolveu com o objetivo de formar pastores, enfermeiros e professores a fim de atender os objetivos essenciais (missão) do movimento adventista (também influenciados por White): pregar, curar e ensinar.

\section{A materialização da Filosofia de Ellen G. White nas estruturas organizacionais adventistas no Brasil}

Ao encontro da Filosofia Whiteana, desde a sua implantação no Brasil, a Igreja Adventista do Sétimo Dia — IASD estrutura-se internamente como uma instituição com “[...] uma tendência de gerar ainda mais estruturas organizacionais." (GREENLEAF, 2011, p. 20). Inicia-se um programa de missões estrangeiras, incluindo em seu roteiro a América do Sul. Os adventistas missionários norte-americanos vindos para América do Sul

[...] não eram imigrantes, segundo a definição tradicional, nem ativistas, tampouco materialistas. No entanto, planejavam ficar, fazer-se ouvir e atribuir um bom uso a

\footnotetext{
${ }^{4}$ Fundamentos da Educação Cristã trata-se de compilação póstuma de artigos de Ellen G. White originalmente publicados em outros livros ou revistas.

${ }^{5}$ Disponível em: <http://ellenwhite.cpb.com.br/livro/index/20>. Acesso em: 01 jun. 2018.
} 
todos os recursos que encontrassem. [...] para marcar seu caminho, deixaram igrejas, escolas, hospitais, fábricas de produtos alimentícios, casas publicadoras e lanchas médicas. (GREENLEAF, 2011, p. 21).

Inicialmente, os primeiros adventistas chegaram ao Sul em terras Argentinas. Posteriormente, se introduzem no Brasil por volta de 1893, com a chegada, vindo dos Estados Unidos, do colportor Albert B. Stauffer ${ }^{6}$, que inicia seus trabalhos missionários na região paulista de Rio Claro, Piracicaba e, posteriormente, possivelmente por sua ascendência alemã, dirige-se às colônias de falas alemãs e inglesas em Santa Catarina e Paraná (GREENLEAF, 2011; PEVERINE, 1988). Chegam, em seguida, os pastores Nowlen ${ }^{7}$ e Snyders ${ }^{8}$, ambos americanos, os quais iniciaram os trabalhos evangelísticos na mesma região. Como não havia material institucional adventista em português (toda a literatura de que dispunham era em inglês ou alemão), optaram por atuar na região sul do país, junto às colônias alemãs. Após os primeiros colportores relatarem aos líderes nos Estados Unidos que no Brasil já havia alguns adeptos do adventismo, esses resolveram enviar um novo pastor, Frank H. Westphal ${ }^{9}$, a partir de 1894, que iria atuar nas comunidades adventistas na Argentina, Uruguai e Brasil com o fim de estruturá-las. Após alguns dias em solo brasileiro, “[...] fenômeno que ocorreu em fevereiro de 1895, Westphal teve a oportunidade de realizar mais de 20 batismos, 'sendo o primeiro deles

\footnotetext{
${ }^{6}$ A. B. Stauffer, americano de origem alemã, foi o primeiro vendedor de livros adventistas (colportor) na Argentina, Uruguai e Brasil. Em 1892, acompanhou Elwin Winthrop Snyder e C. A. Nowlen à Argentina, onde vendeu publicações aos colonos alemães. Em 1893, foi ao Uruguai onde trabalhou entre os colonos suíços e alemães. Em maio do mesmo ano veio ao Brasil, sendo o primeiro colportor a entrar no país. Nos primeiros anos do século XX, assumiu posições administrativas no Sul do país. Disponível em: <http://www.unasp-

ec.com/memoriadventista/enciclopedia/8/032s_stauffer_albert.htm>. Acesso em: 24 jul. 2018.

${ }^{7}$ Sobre o Pastor C. A. Nowlen, não foi possível localizar sua biografia.

${ }^{8}$ E. W. Snyders, pioneiro, colportor e missionário adventista na Argentina, Brasil, Uruguai e Paraguai e Cuba. Disponível em: <http://www.unaspec.com/memoriadventista/enciclopedia/8/043s_elwin_snyder.htm>. Acesso em: 24 jul. 2018. ${ }^{9}$ F. H. Westphal, adventista pioneiro. Nasceu no dia 14 de abril de 1873, num navio, quando seus pais vinham da Alemanha para o Brasil. Sob sua supervisão, foi fundada a primeira Igreja Adventista do Sétimo Dia no Brasil, em Gaspar Alto, SC, organizada em fevereiro de 1896. Faleceu e foi sepultado no dia 24 de fevereiro de 1926, aos 52 anos de idade, em Vitória, ES. Disponível em: <http://www.unaspec.com/memoriadventista/enciclopedia/8/007w_westphal_gustavo.htm>. Acesso em: 24 jul. 2018.
} 
Guilherme Stein $\mathrm{Jr}^{10}$, filho de imigrantes da Suíça e Alemanha’ [...] Com o batismo de Stein, inicia-se formalmente a história da Igreja Adventista do Sétimo Dia no Brasil” (p. 52).

A liderança da IASD da América do Norte, em especial os que eram responsáveis pela Comissão de Missões Estrangeiras, ao tomarem conhecimento da variedade linguística que existia entre os imigrantes que estavam chegando ao Brasil, viam a educação como uma forte ferramenta para o proselitismo religioso (MENSLIN, 2015).

Assim, empreender um projeto missionário-educacional fazia parte dos planos dos primeiros adventistas que aqui chegaram. Além da preocupação com a disseminação da doutrina, passaram a se preocupar com a educação dos seus filhos e dos recém-conversos, buscando oferecer a eles uma educação evangelizadora dentro dos princípios religiosos e defendidos pela instituição (GROSS, 1996; VIEIRA, 1996). Com isso, assim que chegaram, buscaram criar escolas paroquiais. Embora muitas delas tenham surgido pequenas e sem muita projeção social, foram progressivamente crescendo e, em alguns momentos, enfrentando dificuldades financeiras e administrativas.

\footnotetext{
${ }^{10} \mathrm{G}$. Stein Jr., descendente de imigrantes alemães, por parte do pai, e de imigrantes suíços, do lado materno, nasceu em Campinas (SP), no dia 13 de novembro de 1871. Foi o primeiro brasileiro a tornar-se membro da Igreja Adventista do Sétimo Dia, professor e fundador da primeira escola Adventista no Brasil. Em abril de 1895 uniu-se oficialmente ao adventismo. A partir daí abandonou o trabalho na Oficina e passou a vender literatura Adventista, escrita em inglês, na região de Santa Bárbara, onde se localizavam colônias de americanos. No ano seguinte, partiu com a esposa para Curitiba (PR), onde tornou-se professor no Colégio Internacional de Curitiba, cujas atividades iniciaram-se em $1^{\circ}$ de julho de 1896 , como iniciativa de membros leigos adventistas. Em 15 de outubro de 1897, Guilherme Stein Jr fundou, em Gaspar Alto (SC), a primeira escola Adventista missionária do Brasil. Dois anos depois, Guilherme Stein Jr e família deslocaram-se para o Rio de Janeiro a fim de iniciar a publicação de um periódico adventista no Brasil, intitulado O Arauto da Verdade. Em 1900 tornou-se o primeiro brasileiro a ser credenciado como Ministro (Pastor Evangélico) pelos Adventistas do Sétimo Dia. Em 1904, transferiu-se para o Rio Grande do Sul e trabalhou na direção do Colégio Adventista de Taquari. Depois de breve permanência nesse colégio em terras gaúchas, Guilherme Stein Jr retornou ao interior paulista e fixou residência em Rio Claro e, posteriormente, São Bernardo, dedicando-se ao trabalho de Editor na imprensa Adventista até a sua aposentadoria em 1918. Faleceu em 05 de outubro de 1957, em São Paulo. Disponível em: <http://www.histedbr.fe.unicamp.br/navegando/glossario/verb_b_guilh erme_stein_jr.htm>. Acesso em: 24 jul. 2018.
} 
Concomitantemente, foi criada a primeira escola em Curitiba-PR ${ }^{11}$, tendo como objetivo oferecer educação aos filhos dos missionários e novos conversos.

Em 1897 fundou-se a escola missionária de Gaspar Alto, próximo a Brusque-SC, que posteriormente foi transferida para Taquari-RS (1903), por ser uma região com maior presença de adventistas à época. As aulas se iniciaram em 19 de agosto de 1903 e a escola funcionava em regime de internato e externato misto (coeducação), situação bastante inovadora para o momento. Segundo Stencel (2006, p. 67), “[...] essas duas pequenas escolas lançaram as bases e serviram como o marco inicial daquela que se tornaria a primeira escola superior adventista no Brasil, o Instituto Adventista de Ensino (IAE)".

Os anos seguintes foram de intensas tomadas de decisões em relação aos encaminhamentos da educação adventista. Em 1910, a Conferência do Rio Grande do Sul, sede administrativa da IASD na região, recomendou a transferência da instituição para uma região mais centralizada, fechando assim a Escola Missionária de Taquari. No ano seguinte a propriedade foi vendida. Somente em 1915, após reunião da Assembleia da Missão Paulista, efetivamente se escriturava o imóvel em nome da Associação dos Adventistas do Sétimo Dia do Brasil (MENSLIN 2015).

Quase imediatamente após a consolidação do negócio, transferiram-se para a propriedade o casal John Boehm e Augusta Boehm ${ }^{12}$ para dar início ao

${ }^{11}$ Sobre a história do Colégio Adventista de Curitiba, consultar Gross (1996) e Vieira (1996).

${ }^{12}$ Augusta Boehm, cofundadora do Colégio Adventista Brasileiro (CAB), atual UNASP, professora e preceptora. Nasceu numa fazenda em Kansas, EUA, em 1888. Filha mais velha do senhor Schneider, era dedicada ao trabalho, ao estudo da Bíblia e a Deus. Ainda jovem, ingressou no Union College, em Lincoln, Nebraska, onde foi aluna interna até o término de seu curso de Pedagogia. Formou-se em 1908 nesta escola e concluiu a Faculdade de Enfermagem em Loma Linda, em meados de 1912. Após sua formatura em 1908, lecionou na escola primária de sua igreja em Kansas. Antes de ingressar para o internato, conheceu John Boehm, que trabalhava na fazenda auxiliando seu pai. Casaram-se em agosto de 1909 e da união conjugal nasceram dois filhos: Oliver, que faleceu logo após o parto, e Harley Boehm, em julho de 1924, na Califórnia. Seu maior desejo era ser missionária em campos brasileiros e, no dia $1^{\circ}$ de março de 1913, o casal chegou a São Paulo. No início da obra educacional em 1915, também auxiliou na fundação do CAB. Enquanto o marido construía, ela ficava nas barracas como enfermeira, conselheira, preceptora e orientadora no preparo dos alimentos. John Boehm foi convidado para visitar o Paraná em junho de 1918, e Augusta permaneceu até o dia 21 de outubro de 1919 no Colégio. No final de 1923, ela enfrentou alguns problemas com malária e o esposo, com insuficiência cardíaca. Seguiram, então, para o Hospital Adventista de Washington, Califórnia, EUA. Em 1930, voltaram para o Brasil e, aproximadamente na década de 1940, ela serviu novamente como preceptora e 
internato/externato e centro educacional da IASD no Brasil, responsável pela formação de grande parte dos missionários, pastores, enfermeiros, professores e demais profissionais que viriam a compor o quadro administrativo ligado à IASD no país. Inicialmente, na sua fundação, em 1915, recebeu o nome de Collegio Missionário da Conferência da União Brasileira dos Adventistas do Sétimo Dia. Posteriormente, Seminário Adventista, Colégio Adventista Brasileiro, Instituto Adventista de Ensino e, finalmente, a partir de 1999, Centro Universitário Adventista de São Paulo (UNASP).

Tendo como matriz filosófica os princípios whiteanos, as instituições educacionais adventistas sempre primaram pela manutenção de suas ideias na condução das suas escolas de educação básica e superior.

Com base nesse pensamento, a Conferência Geral (CG) dos Adventistas, órgão direcional mundial da IASD, publicou documento intitulado Declaraşão da Filosofia Educacional Adventista do Sétimo Dia (2003) que sintetiza o pensamento da autora e o coloca de forma didática numa sequência de princípios elencados em premissas básicas. Sobre a filosofia educacional adventista, tais "Premissas" são as seguintes:

- A filosofia educacional da Igreja Adventista do Sétimo Dia é centrada em Deus. Os adventistas creem que sob a direção do Espírito Santo, o caráter e os propósitos de Deus podem ser compreendidos como revelados na Bíblia, em Jesus Cristo e na natureza. As caraterísticas distintivas da educação adventista derivadas da Bíblia e dos escritos de Ellen G. White destacam o propósito redentor da verdadeira educação: restaurar seres humanos à imagem do seu Criador. Os adventistas do sétimo dia creem que Deus é infinitamente amoroso, sábio e poderoso. Ele se relaciona com os seres humanos num nível pessoal e apresenta Seu caráter como a norma suprema para a conduta humana.

- Os adventistas reconhecem, contudo, que os motivos humanos, o pensar e a conduta não satisfazem o ideal de Deus. A educação em seu sentido mais amplo é um meio de restaurar seres humanos a seu relacionamento original com Deus. Operando juntos, lares, escolas e igrejas cooperam com as agências divinas em preparar os estudantes para uma cidadania responsável neste mundo e no mundo porvir.

- A educação adventista provê mais do que conhecimento acadêmico. Promove um desenvolvimento equilibrado da pessoa toda - espiritualmente, intelectualmente,

auxiliando na área de música como pianista no Instituto Adventista Cruzeiro do Sul (IACS). Em 1954, o casal regressou aos Estados Unidos, fixando residência em La Sierra, Califórnia, para estarem mais próximos dos parentes. Augusta faleceu no dia 14 de abril de 1967, aos 79 anos de idade, no hospital para convalescentes em Loma Linda, Califórnia. Disponível em: <http://www.unasp-

ec.com/memoriadventista/enciclopedia/8/027b_boehm_augusta.htm>. Fonte: João Rabello, John Boehm - Educador Pioneiro; Revista Adventista, agosto de 1967, p. 32. Acesso em: 28 jul. 2018. 
fisicamente e socialmente. Ela abarca a eternidade. Procura desenvolver uma vida de fé em Deus e respeito pela dignidade de todos os seres humanos; formar caracteres semelhantes ao do Criador; encorajar pensadores em vez de meros refletores dos pensamentos de outros; promover serviço amorável em vez de ambição egoísta; assegurar o máximo desenvolvimento do potencial de cada indivíduo; e a abraçar tudo que é verdadeiro, bom e belo (CONFERÊNCIA GERAL, 2003). ${ }^{13}$

Ainda em conformidade com a filosofia institucional, E. M. Cadwallader faz uma retomada desses princípios em um documento intitulado Filosofia Básica da Educação Adventista (2006) ${ }^{14}$ :

1. A única educação verdadeira é a cristã ou a educação que inclui o ensino religioso baseado na Bíblia;

2. O processo educacional está preocupado com o indivíduo por completo durante todo o período de sua existência;

3. A educação deve ser prática, bem como cultural e acadêmica;

4. A educação deve preparar uma pessoa para ser útil e deve inspirá-la com o ideal de serviço;

5. O currículo deve ser suficientemente vocacional para assegurar que todo aluno deixe a escola com meios dignos para ganhar seu sustento;

6. A política educacional não deve ser limitada pela tradição;

7. É obrigação da Igreja educar todos os seus membros, sejam adultos ou crianças;

8. Uma localização rural e pitoresca é ideal para um internato;

9. A maior parte possível do trabalho de cuidar da instituição deve ser feita pelos estudantes e todos devem ter algum trabalho de experiência;

10. Os professores devem ser bem qualificados academicamente, mas acima de tudo, devem ser cristãos praticantes imbuídos do espírito missionário;

11. A saúde é um fator primordial no sucesso do aluno; tanto a escola como o aluno devem estar preocupados com os princípios de saúde;

12: A verdadeira educação é o desenvolvimento harmônico dos aspectos físicos, mentais, morais, espirituais, estéticos, vocacionais, emocionais, sociais e religiosos da natureza humana;

13. A Bíblia deve ser considerada o livro mais importante em todos os níveis de educação (CADWALLADER, 2006, p. 89).

White também escreveu muitos conselhos e recomendações em relação à educação para os adventistas e novos conversos, destacando pontos essenciais sobre

\footnotetext{
${ }^{13}$ Disponível em: <http://circle.adventist.org/download/PhilStat03_Po.pdf>. Acesso em: 15 jul. 2018.

${ }^{14}$ Este documento resulta da tradução da tese doutoral defendida pelo Dr. E. M. Cadwallader, cujo título original é Principles of Education in the Writings of Ellen G. White [Princípios da Educação nos Escritos de Ellen G. White], na qual se efetuou um estudo sistematizado nos escritos de Ellen G. White quanto a sua filosofia educacional. Este documento foi traduzido sob a coordenação do Dr. Renato Stencel, diretor do Centro Nacional da Memória Adventista e Centro de Pesquisas Ellen G. White.
} 
a instrução das crianças e jovens e sobre o trabalho educativo a ser desenvolvido ${ }^{15}$, a saber: a compreensão da educação, a fonte da sabedoria, sobre a verdadeira educação, sobre a educação essencial ao jovem, a educação e o pensamento independente, sobre o ensino religioso e estudo da bíblia, sobre o estudo da língua, sobre o estudo dos números, sobre o ensino da História, sobre o ensino das Ciências, sobre o uso de ficção de baixo valor, sobre a Educação Física, sobre o ensino da Música e sobre o trabalho manual.

Por fim, para White, a aprendizagem dos alunos é constante e perene, estendendo-se por toda a vida e por toda a eternidade.

\section{Perfil do professor na filosofia adventista}

Desde os primórdios da IASD, a questão educacional se fazia tão importante quanto a obra de evangelização. A valorização da pessoa do mestre, o modelo de conduta a ser observado e até imitado pelos alunos, sempre foi fator ressaltado em documentos da igreja. Na Declaração da Filosofia Educacional Adventista do Sétimo Dia da Conferência Geral da IASD, estão descritas sucintamente algumas orientações a respeito do perfil do professor. "Idealmente, o professor deveria ser tanto um cristão adventista dedicado como um modelo das graças cristãs e competência profissional" (CONFERÊNCIA GERAL, 2003).

Da mesma forma, White (1977) apresenta algumas características que são apontadas como necessárias para que o professor exerça sua função de forma a atuar em consonância com os princípios da filosofia adventista:

Os professores de nossas escolas têm pesada responsabilidade a cumprir. Devem ser em suas palavras e caráter o que desejam que seus estudantes se tornem: homens e mulheres que temam a Deus e pratiquem a justiça. Se eles mesmos conhecem o caminho, podem preparar a juventude a andar nele. Não somente os educarão nas ciências, mas os ensinarão a ter independência moral, a trabalhar por Jesus, e a assumir encargos em Sua causa (WHITE, 1977, p. 48).

\footnotetext{
${ }^{15}$ Apenas neste tópico, a consulta aos livros de White foi realizada em ambiente virtual, por meio do site da Casa Publicadora Brasileira (CPB) - Editora adventista que detém os direitos autorais, portanto, não constam datas de publicação ou edição. Disponível em: <http://ellenwhite.cpb.com.br/livro/index/36> Acesso em: 07 jan. 2018.
} 
Os professores têm a fazer por seus alunos mais que thes comunicar conhecimento tirado de livros. Sua posição como guias e instrutores da juventude é por demais cheia de responsabilidade, pois é-lhes dada a obra de moldar o espírito e o caráter. Os que empreendem essa obra devem possuir caráter bem equilibrado, simétrico. Devem ter maneiras finas, ser corretos no vestuário e cuidadosos em todos os hábitos; e devem possuir aquela cortesia cristã que conquista a confiança e o respeito. O professor deve ser aquilo que deseja que seu aluno se torne. (WHITE, 1977, p. 65).

A verdadeira educação não desconhece o valor dos conhecimentos científicos ou aquisições literárias, mas, acima da instrução, aprecia a capacidade; acima da capacidade, a bondade; e acima das aquisições intelectuais, o caráter. O mundo não necessita tanto de homens e mulheres de grande intelecto, quanto de nobre caráter. Precisa de homens e mulheres cuja habilidade seja dirigida por princípios firmes. (WHITE, 1977, p. 225).

Observa-se nos excertos anteriores, em seu texto Educaşão (1977), que White busca conciliar os preceitos religiosos com os conhecimentos científicos sobre educação. Entretanto, acaba sobrepondo os preceitos religiosos aos científicos. Também em Fundamentos da Educação Cristã é possível observarmos esse tom conciliatório, aspecto marcante em toda sua obra.

Deus não quer que nos satisfaçamos com mente preguiçosa, indisciplinada, pensamentos obtusos e memória fraca. Quer que todo professor seja eficiente, não se contentando, apenas, com certa medida de êxito, mas compreendendo sua necessidade de constante diligência em adquirir conhecimento (WHITE, 1975b, p. 119).

Conquanto o professor tenha de ser firme e decidido, não deve ser opressor e ditatorial. Ser áspero e severo, ficar longe de seus discípulos, ou tratá-los indiferentemente, corresponde a fechar a passagem pela qual poderia influir neles para o bem (WHITE, 1977, p. 280).

Ainda em tenra idade, devem as crianças ser ensinadas a ler, a escrever, a compreender os números, a fazerem suas próprias contas. Podem prosseguir passo a passo neste conhecimento. Mas, antes de tudo, deve ensinar-se-lhes que 0 temor do Senhor é o princípio da sabedoria (WHITE, 1975a, p. 150).

Todo professor deve cuidar de que seu trabalho tenda a resultados definidos. Antes de tentar ensinar uma matéria, deve ter em seu espírito um plano distinto, e saber o que precisamente deseja conseguir (WHITE, 1977, p. 233).

Todas as matérias desnecessárias devem ser extirpadas dos cursos de estudo, e oferecidas ao aluno unicamente os estudos que the forem de real valor (WHITE, 1975b, p. 447). 
Entretanto, como escritora e estudiosa das questões educacionais, as especificidades das idades dos alunos são resguardadas nos escritos de White, o que evidencia suas apropriações sobre as ideias educacionais da época.

\section{Considerações finais}

Para se pensar aspectos históricos educacionais, é possível concluirmos, ao encontro das afirmações de outros pesquisadores, que o pensamento de Ellen White e, consequentemente, da igreja adventista sobre educação surge num contexto histórico de ressurgimento de ideias educacionais que valorizavam os pensamentos de Rousseau e Condorcet, como também das ideias de Kant e de Pestalozzi.

Nesse sentido, White, escritora e estudiosa das questões educacionais, buscou estabelecer um paralelo entre as ideias educacionais da época e a redenção que nortearia toda a filosofia adventista de educação. Com isso, colocou diante dos membros e fiéis seguidores os princípios que deveriam conduzir a educação dos jovens e que, por fim, se consolidaram como alicerces da filosofia educacional adventista até os dias atuais.

Os princípios educacionais adventistas estão presentes em toda a sua rede mundial de educação e foram concebidos a partir de uma visão bíblico-cristã sistematizada em forma de cartas, livros e escritos diversos pela escritora Ellen G. White, entre as décadas de 1870, quando a autora começa a escrever sobre a instrução para a educação das crianças e jovens adventistas, e 1915, ano de seu falecimento. Boa parte dos seus escritos sobre o tema está pulverizada em muitas de suas obras. No entanto, a grande maioria se concentra nos livros mencionados: Educação (1977), Conselhos aos Professores, Pais e Estudantes (1975a) e Fundamentos da Educação Cristã (1975b), entre outros. Alguns desses livros foram escritos por ela e outros, frutos de compilações póstumas. Em complementação, White destaca pontos sobre o perfil do professor.

Por fim, como mencionado na introdução deste artigo, para se entender a filosofia educacional adventista é necessário considerar o papel dos escritos de Ellen G. White e seu protagonismo na organização da instituição, tanto como igreja 
quanto como instituição educacional. Nesse sentido, buscamos reunir alguns dos aspectos desse seu protagonismo sobre o pensamento dos adventistas na área da educação, os quais também se materializaram em mesmo grau de importância em outras áreas, como saúde, nutrição e religião.

\section{Referências}

BARBANTI, M. L. H. Escolas americanas de confissão protestante na provincia de São Paulo: um estudo de suas origens. 1977. 228 f. Dissertação (Mestrado em Educação) — FEUSP, São Paulo, 1977.

BOAVENTURA, E. Educação Metodista no Brasil origem e ideologia. Dissertação (Mestrado em Educação) - Universidade Metodista de Piracicaba, Piracicaba, 1978.

BURKE, P. O que é história Cultural? Trad. PAULA, S. G. de. Rio de Janeiro: Zahar, 2011.

CALVANI, C. E. Educação no projeto Missionário do protestantismo no Brasil. Rev. Pistis Prax., Teol. Pastor., Curitiba, v. 1, n. 1, p. 53-69, jan./jun. 2009.

CADWALLADER, E. M. Filosofia básica da educação adventista. 2006. Disponível em: $<$ http://www.adventista.edu.br/_imagens/area_academica/files/CADWALLADER $\% 20 \mathrm{E} \% 20 \mathrm{M}$ $\% 20-020$ Filosofia $\% 20 \mathrm{~B} \% \mathrm{C} 3 \%$ A 1 sica $\% 20 \mathrm{da} \% 20$ Eduacao $\% 20$ Crista $\% 20$ com $\% 20$ realce.pdf $>$.

Acesso em: 15 jan. 2019.

CERTEAU, M. de. A escrita da história. Rio de Janeiro: Forense-Universitária, 1982.

CHARTIER, R. A história cultural: entre práticas e representações. Trad. GALHARDO, M. M. Lisboa: DIFEL; Rio de Janeiro: Bertrand Brasil, 1990.

CONFERÊNCIA GERAL. Declaração da Filosofia Educacional Adventista do Sétimo Dia: Premissas. 2003. Disponível em: < http://circle.adventist.org/download/PhilStat03_Po.pdf>. Acesso em: 15 jul. 2018.

GREENLEAF, F. Terra de esperança: o crescimento da igreja Adventista do Sétimo dia na América do Sul. Trad. NASCIMENTO, C. E. Tatuí: CPB, 2011.

GROSS, R.; GROSS, J. S. Filosofia da educação cristã: uma abordagem adventista. Tatuí: CPB, 2012.

GROSS, R. Colégio Internacional de Curitiba. Rio de Janeiro: Collins Editora, 1996.

HACK, O. H. Protestantismo e Educação Brasileira (presbiterianismo e seu relacionamento com o Sistema Pedagógico). São Paulo: Casa Editora Presbiteriana, 1985.

KNIGHT, G. R. A dinâmica da expansão educacional: uma lição da História Adventista. In: TIMMM, A. (Org.) A educação Adventista no Brasil: uma história de aventuras e milagres. Engenheiro Coelho: Unaspress, 2004.

KNIGHT, G. R. Oberlin College and Adventist educational reforms. Adventist Heritage. Spring 1983. 
LÉONARD, É. G. O protestantismo Brasileiro: Estudos de Eclesiologia e História Social. Trad. SCHÜTZER, L. de C. 2. ed. Rio de Janeiro e São Paulo, JUERP/ASTE, 1981.

MENDONÇA, A. G. Introdução ao Protestantismo no Brasil. São Paulo: Edições Loyola, 1990.

MENSLIN, D. Educação Adventista: 120 anos de escolas paroquiais a uma rede de ensino: permanências e rupturas de um ideário educacional. Curitiba: Ed. DVK, 2015.

PEVERINE, H. En las huellas de la providencia. Buenos Aires: ACES, 1988.

RAMALHO, J. P. Prática Educativa e Sociedade. Rio de Janeiro: Zahar Editores, 1976.

REILY, D. A. História documental do protestantismo no Brasil. São Paulo: ASTE, 1984.

SALES, G. G. P. A Faculdade Adventista de Educação - FAED (1973-1999) e sua contribuição para a formação de professores adventistas no Brasil. Marília, 2019, 415f. Tese (Doutorado em Educação) - Universidade Estadual Paulista, Faculdade de Filosofia e Ciências, Marília, 2019.

SCHWARZ, R.; GREENLEAF, F. Portadores de luæ: história da Igreja Adventista do Sétimo Dia. Engenheiro Coelho: UNASPRESS, 2009.

SCHULZ, A. Educação superior protestante no Brasil. Engenheiro Coelho: UNASPRESS, 2003.

STENCEL, R. A educação adventista de nível superior no Brasil. In: TIMM, A. R. (Org.). A educação adventista no Brasil: uma história de aventuras e milagres. Engenheiro Coelho: Unaspress, 2004.

STENCEL, R. História da educação superior adventista no Brasil. Piracicaba, 2006, 275f. Tese (Doutorado em Educação) — Universidade Metodista de Piracicaba, Faculdade de Ciências Humanas, Piracicaba, 2006.

VIEIRA, R. C. de C. Centenário da Educaşão Adventista no Brasil (1896 - 1996). Destacando a contribuição de um pioneiro. Brasília, DF, 1996.

WHITE, E. G. Conselhos aos Professores, Pais e Estudantes. Santo André: Casa Publicadora Brasileira, 1975a.

WHITE, E. G. Fundamentos da Educação Cristã. Tatuí: Casa Publicadora Brasileira, 1975b.

WHITE, E. G. Educação. Santo André: Casa Publicadora Brasileira, 1977.

RECEBIDO: 16/09/2019

APROVADO: 05/02/2020

RECEIVED: 09/16/2019

APPROVED: 02/05/2020

RECIBIDO: $16 / 09 / 2019$

APROBADO: 05/02/2020 